Viso: Cadernos de estética aplicada

Revista eletrônica de estética

ISSN 1981-4062

No 29, jul-dez/2021

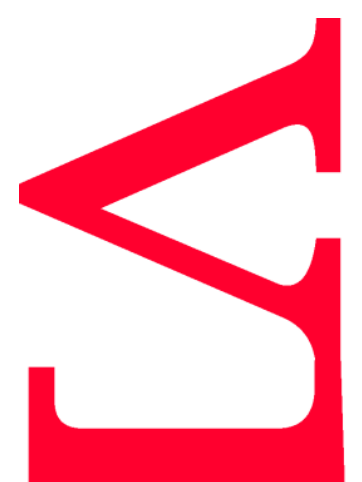

http://www.revistaviso.com.br/

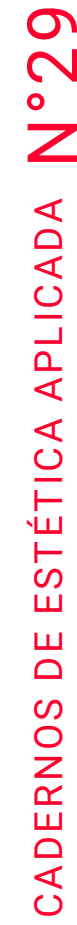

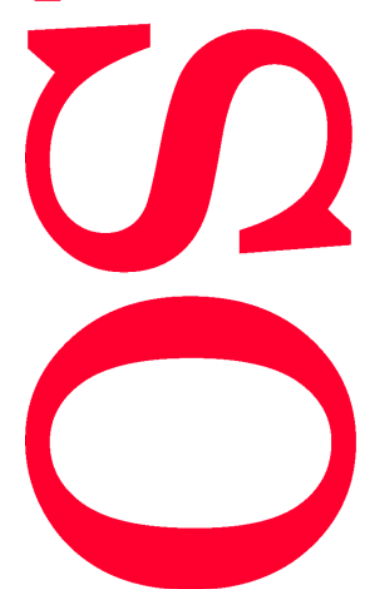

\title{
A dimensão estética em tempos de contágio
}

\section{Imaculada Kangussu}




\section{RESUMO}

A dimensão estética em tempos de contágio

A partir do recurso às diversas formas de espetáculos como conforto à reclusão durante a quarentena imposta pela pandemia, refletimos sobre e colocamos mais questões do que respostas às necessárias narrativas imagéticas.

Palavras-chave

quarentena; imagem; reprodutibilidade técnica; afecção

\section{ABSTRACT}

\section{Aesthetic Dimension in Times of Contagion}

Considering the use of various forms of spectacle used as a sort of comfort during the quarantine imposed by the pandemic, we reflect on and pose more questions the answers to the necessary imagistic narratives.

Keywords

quarantine; image; technical reproducibility; affection 


\section{KANGUSSU, Imaculada. "A dimensão estética em tempos de contágio". Viso: Cadernos de estética aplicada, v. 15, $n^{\circ} 29$ (jul-dez/2021), p. 213-224.}

DOI: $10.22409 / 1981-4062 / v 29 i / 414$

Aprovado: 30.10.2021. Publicado: 30.01.2022.

(C) 2021 Imaculada Kangussu. Esse documento é distribuído nos termos da licença Creative Commons Atribuição-NãoComercial 4.0 Internacional (CC-BY-NC), que permite, exceto para fins comerciais, copiar e redistribuir o material em qualquer formato ou meio, bem como remixá-lo, transformá-lo ou criar a partir dele, desde que seja dado o devido crédito e indicada a licença sob a qual ele foi originalmente publicado.

Licença: http://creativecommons.org/licenses/by-nc/4.0/deed.pt_BR

Accepted: 30.10.2021. Published: 30.01.2022.

(C) 2021 Imaculada Kangussu. This document is distributed under the terms of a Creative Commons Attribution-NonCommercial 4.0 International license (CC-BY-NC) which allows, except for commercial purposes, to copy and redistribute the material in any medium or format and to remix, transform, and build upon the material, provided the original work is properly cited and states its license.

License: $\underline{\text { http://creativecommons.org/licenses/by-nc/4.0/ }}$ 
Logo nos primeiros meses de 2020, fomos submetidas à necessidade de mantermos distância física umas das outras, em escala global, pelo vírus da Covid-19, letal, propagado no ar com rapidez jamais vista antes.

O confinamento doméstico, para quem tem os meios necessários a ele, transforma profundamente a relação com o entorno, com a dimensão estética pode-se dizer, tanto no sentido original do termo quanto no sentido a ele atribuído pela filosofia.

Talvez mais forte do que uma nova percepção da paisagem doméstica tenha sido a da necessidade de recurso aos produtos da (vamos chamar de) arte - sejam aos portadores de expressões autênticas, sejam aos da cultura de massa, da sociedade do espetáculo, da indústria cultural, ou qualquer que seja o nome dado a essa esfera mercadológica que produz imagens fantasmagóricas a metro, em série, a partir de taxonomias dos desejos, rigorosamente estudadas.

Pensando a dimensão estética na época de quarentena, dois textos da fabulosa herança filosófica surgiram imediatamente em meu pensamento: "A obra de arte na era de sua reprodutibilidade técnica", de Walter Benjamin e $A$ peste, de Albert Camus.

Bastante conhecido, muitas vezes através de equivocadas interpretações nas quais surge como um paladino da reprodutibilidade técnica - ao alto custo de deixar de lado o movimento dialético, realizado por Benjamin, capaz de perceber perdas e ganhos no processo - o texto sobre "A obra de arte na era de sua reprodutibilidade técnica" é potente, sobretudo, pela visão histórica da percepção humana nele desenvolvida.

Além da mudança histórica nas formas de perceber e das transformações na relação entre a obra e o fruidor, trazidas pela reprodutibilidade técnica e ressaltadas por Benjamin, a de maior efeito (e utilidade) no momento atual é a de aproximar o indivíduo da obra, através de reproduções. "A reprodução técnica pode colocar a cópia do original em situações 
impossíveis para o próprio original [...] A catedral abandona seu lugar para instalar-se no estúdio de um amador; o coro, executado ao ar livre, pode ser ouvido num quarto". ${ }^{1} \mathrm{~A}$ autonomia da reprodução técnica é muito mais ampla que a do original, e pode propiciar a denominada "democratização" da arte.

Em compensação, a obra é arrancada à tradição, perde a dimensão de autenticidade, a "aura", seu testemunho histórico material. "Mesmo que as novas circunstâncias deixem intato o conteúdo da obra de arte, elas desvalorizam, de qualquer modo, o seu aqui e agora". ${ }^{2}$

A reprodutibilidade técnica transforma não apenas a relação dos indivíduos com as obras, como também o próprio fazer artístico ao tornar-se, ela mesma, uma forma de arte, como a fotografia e o cinema. A reprodução técnica pode não apenas "transformar em seus objetos a totalidade das obras de arte tradicionais, submetendo-as a transformações profundas, como conquistar para si um lugar próprio entre os procedimentos artísticos". ${ }^{3}$ Indo em frente com palavras de Benjamin:

Muito se escreveu, no passado, de modo tão
sutil quanto estéril, sobre a questão de saber
se a fotografia era ou não uma arte, sem que
se colocasse sequer a questão prévia de saber
se a invenção da fotografia não havia alterado
a própria natureza da arte [...] Mas as
dificuldades com que a fotografia confrontou
a estética tradicional eram brincadeiras
infantis em comparação com as suscitadas
pelo cinema. ${ }^{4}$

Transitoriedade e repetitividade fazem parte da natureza da arte produzida tecnicamente. A arte passa por uma "refuncionalização", visível especialmente no cinema, sobretudo se comparado à produção da chamada pré-história. Nesta, o que hoje se considera como "obra de arte" era considerado instrumento ritualístico com funções práticas ao qual se atribuíam efeitos mágicos. Conforme Benjamin:

A produção artística começa com imagens a serviço da magia. O que importa, nessas imagens, é que elas existem, e não que sejam 
vistas. 0 alce, copiado pelo homem paleolítico nas paredes de sua caverna, é um instrumento de magia, só ocasionalmente exposto aos olhos dos outros homens: no máximo ele deve ser visto pelos espíritos. ${ }^{5}$

Enquanto a função do cinema, de acordo com Benjamim, é "fazer do gigantesco aparelho técnico de nosso tempo o objeto das inervações humanas - é essa a tarefa histórica cuja realização dá ao cinema o seu verdadeiro sentido". ${ }^{6}$ Benjamin ressalta que a reprodução em massa corresponde à reprodução das massas. "Orientar a realidade em função das massas e as massas em função da realidade é um processo de imenso alcance, tanto para o pensamento quanto para a intuição". ${ }^{7} 0$ surgimento das grandes massas urbanas - fenômeno decorrente da tecnologia capaz de levar a cabo a revolução industrial e a consequente necessidade de mão de obra concentrada nas fábricas coincide com o da sociedade dominada pela chamada "segunda natureza", pelo aparato tecnológico. Diante da segunda natureza, criada pela humanidade que não a controla, "somos obrigados a aprender, como outrora diante da primeira. Mais uma vez, a arte põe-se a serviço desse aprendizado. Isso se aplica, em primeira instância, ao cinema". ${ }^{8}$ Em outra passagem, sobre o mesmo tema, pode-se ler: "Uma das funções mais importantes do cinema é criar um equilibrio entre o homem [sic] e o aparelho". ${ }^{9}$

O problema é o fato de o caráter emancipatório do cinema ser bloqueado pela exploração capitalista dessa linguagem. Segundo Benjamin,

a indústria cinematográfica tem todo interesse em estimular a participação das massas através de concepções ilusórias e especulações ambivalentes. Seu êxito maior é com as mulheres. Com esse objetivo, ela mobiliza um poderoso aparelho publicitário, põe a seu serviço a carreira e a vida amorosa das estrelas, organiza plebiscitos, realiza concursos de beleza. Tudo isso para corromper e falsificar o interesse original das massas pelo cinema, totalmente justificado, na medida em que é um interesse no próprio ser e, portanto, em sua consciência de classe. Vale 
para o capital cinematográfico o que vale para o fascismo em geral: ele explora secretamente, no interesse de uma minoria de proprietários, a inquebrantável aspiração por novas condições sociais. ${ }^{10}$

$\mathrm{Na}$ possibilidade de democratizar a arte, de acordo com Benjamin, o cinema tornou-se o objeto mais importante "daquela ciência de percepção que os gregos chamavam de estética". ${ }^{11}$ Pode-se, atualmente e sem torturar o texto, ampliar "cinema" para as narrativas em forma de imagem em movimento transmitidas pela televisão e por outras telas. Deste modo, soa ainda mais verdadeira a afirmação de que "a recepção através da distração, que se observa crescentemente em todos os domínios da arte e constitui o sintoma de transformações profundas nas estruturas perceptivas, tem no cinema o seu cenário privilegiado". ${ }^{12}$

Perceber "transformações profundas nas estruturas perceptivas" implica, é claro, perceber que a própria percepção não é fruto de uma estrutura apenas natural e sim, também, formada historicamente. "A forma de percepção das coletividades humanas se transforma ao mesmo tempo que seu modo de existência". ${ }^{13}$

Em suma, transformações radicais nos modos de existência acarretam, fatalmente, mudanças nas formas de percepção. $\mathrm{Na}$ inacabada obra das Passagens, Benjamin expõe com clareza os vínculos existentes entre as mudanças sociais e a invenção de fantasmagorias criadas com o objetivo de apresentar narrativas imagéticas de um mundo distinto do de fato existente: um mundo mais harmônico, uma espécie de refúgio imaginário, uma forma de escapar à crescente agressividade e incompreensibilidade da estrutura dominante.

Para sufocar pulsões transformadoras, a dimensão estética tem sido ocupada pela indústria cultural, cujo propósito, além de vender seus produtos industriais, é neutralizar o pensamento, 0 mudo diálogo interior. $\mathrm{Na}$ conhecida sentença de Adorno e Horkheimer, "o esquematismo é o primeiro serviço por ela prestado ao cliente" ${ }^{14} \mathrm{~A}$ função de conhecer - relacionar os 
dados sensíveis e os conceitos do entendimento, que o esquematismo kantiano atribuía ao sujeito - já vem realizada nos produtos da indústria cultural. Nestes, os fenômenos já vêm ajuizados e os conceitos já dotados de figuração sensível, tudo muito fácil de entender e produzido a partir de classificações capazes de incluir diversos níveis de consumidores em seus nichos preferidos.

"Para o consumidor, não há nada mais a classificar que não tenha sido antecipado no esquematismo da produção". Adorno e Horkheimer consideram, em 1944, que o cinema "é o triunfo do capital investido". O sentido de todos os filmes, "não importa o plot escolhido em cada caso pela direção de produção", é sempre gravar a onipotência do capital "no coração dos esbulhados, que se tornaram candidatos a jobs, como a onipotência de seu senhor". ${ }^{15}$ A necessidade imanente ao sistema é a "de não soltar o consumidor, de não lhe dar em nenhum momento $o$ pressentimento da possibilidade de resistência". ${ }^{16} \mathrm{E}$ ao desejo, "o que enfim se serve é o simples encômio do cotidiano cinzento ao qual ele queria escapar". ${ }^{17} \mathrm{Em}$ uma passagem de "A indústria cultural", cuja atualidade faz jus a uma longa citação, pode-se ler:

\begin{abstract}
A cultura sempre contribuiu para domar os instintos revolucionários, e não apenas os bárbaros. A cultura industrializada faz algo a mais. Ela exercita 0 indivíduo no preenchimento da condição sob a qual ele está autorizado a levar essa vida inexorável. 0 indivíduo deve aproveitar seu fastio universal para se abandonar ao poder coletivo do qual está enfastiado [...] Basta se dar conta de sua própria nulidade, subscrever a derrota - e já estamos integrados. A sociedade é uma sociedade de desesperados e, por isso, a presa de bandidos. ${ }^{18}$
\end{abstract}

Tendo em vista a necessidade de ilusões constitutivas (cf. Nietzsche, Freud e Lacan), a indústria cultural encontra acolhida fácil em uma lacuna existente. Mas a lacuna persiste mesmo através da mais agradável experiência estética. De modo difuso, inominado, obsceno, permanece o que não pode vir à cena - sob o risco de interromper a delícia da experiência do pseudo. Para 
que o agradável conforto da arte ilusionista ocorra, momentaneamente, um véu obnubila o que pode atrapalhar. Para permanecer alienada no pseudo, a psique abraça a cegueira e, assim, esta se torna mais e mais intensa. Desviar as vistas do assustador implica viver sob o penoso ofício de negálo.

Distintamente, a utilidade da obra de arte na sociedade agonística é a existência do inútil. Do não instrumentalizável. É a alienação da alienação. A potência das obras de arte (incluindo as cinematográficas) pode ser percebida na capacidade de expressar algo que não poderia vir à tona de outra forma. Em outras palavras, de dar forma ao até então indizível, ao clandestino, e interromper o tecido das falsas narrativas em curso. Assim, as experiências estéticas mais intensas não são as do belo nem do sublime, e sim as do desconcertante. A de se ver em jogo com algo profundamente conhecido e até então sem forma, infigurado, mas o quê? Os sentimentos de prazer e desprazer são simultâneos e se confundem. A experiência do enigma - existente em todo ser vivo - vivifica.

Pode também dilacerar. Talvez seja melhor mesmo permanecer na superfície dos produtos oferecidos pela sociedade do espetáculo, aderir à servidão, abdicar da liberdade pela segurança, adotar a moral do escravizado...

Por outro lado, o desenvolvimento dos costumes (ethos, mores) em eticidade, moralidade, já foi considerado como a espinha dorsal da humanidade (Hegel, Princípios da filosofia do direito). Tal desenvolvimento leva, para além da moralidade senhorescravo, à percepção de que o interesse individual coincide com o interesse coletivo. Atenção: não se trata de substituir o interesse individual, em um gesto de altruísmo incomum, pelo coletivo: na verdade, trata-se de uma mudança na percepção, trata-se de perceber que o interesse individual é o interesse coletivo. Em outras palavras, de que é melhor viver em comunidades responsáveis pelo bem-estar de seus comuns do que em constante e declarada guerra com os vizinhos para proteger interesses privados. Isso é lógica, e precisa ser 
transformada em prática, em costume. É o que a pandemia do Covid tem mostrado com clareza: que o interesse individual é $o$ coletivo; proteger-se é proteger a coletividade e vice-versa. 0 vírus adverte-nos sobre a existência de um destino comum aos seres humanos e à natureza. Ainda que haja personagens insistindo em dilapidar a natureza para alimentar fálicos foguetes e ir além da Terra violentada.

E aqui aparece a incógnita: depois da pandemia, a lembrança de um "destino comum" será intensa o suficiente para transformar o paradigma - baseado na exploração predatória da natureza, sobretudo da humana - atualmente dominante? A resposta não está dada. Se, por um lado, a natureza está mostrando que a forma atual da civilização, origem da pandemia, conduz à destruição e à morte; por outro lado, o desejo predominante parece ser o de voltar à "normalidade", e não, como seria de se esperar, o de transformação... Ora, voltar à "normalidade" implica ter de, em breve, enfrentar novo vírus - ou outra forma de catástrofe - ainda mais fatal... Talvez venhamos a nos lembrar com saudades dos tempos em que podíamos andar no exterior apenas de máscara...

Lembrando (com Thomas Kuhn, entre outras fontes) o forte teor afetivo presente e mesmo determinante nas escolhas, a questão que parece se colocar é como encontrar a forma do afeto capaz de comover tanto o povo submetido por esquemas criminosos quanto os raros bilionários agarrados a seus trilhões ensanguentados? A qual afecção apelar? Qual imagem pode ser tocante? Em linguagem crua, como afetar a "opinião pública" que é a massa de manobra, a bala na agulha? Como suspender a eficiência ideológica em curso, a ideologia dos vencedores, quando o que será encontrado, se atravessada a persona construída com imagens do espetáculo, é a própria fragilidade e o desamparo? Como levar, então, quem prefere a venda, a ver? Como conversar sobre emancipação com quem já aderiu à servidão voluntária? Em suma, qual a palavra que transforma? ${ }^{19}$ 


\section{Referências bibliográficas}

ADORNO, Theodor; HORKHEIMER, Max. "A indústria cultural: o esclarecimento como mistificação das massas". In: Dialética do esclarecimento. Tradução de Guido Antônio de Almeida. Rio de Janeiro: Zahar, 1985.

BENJAMIN, Walter. "A obra de arte na era de sua reprodutibilidade técnica", primeira versão. Magia e técnica, arte e política. Obras escolhidas, volume 1. Tradução de P. Rouanet. São Paulo: Brasiliense, 1995.

KUHN, Thomas. The Structure of Scientific Revolutions. Chicago: The University of Chicago, 1970.

MARCUSE, Herbert. "Sobre o caráter afirmativo da cultura". In: Cultura e sociedade, v. 1. Tradução de Wolfgang Leo Maar. Rio de Janeiro: Paz e terra, 1997.

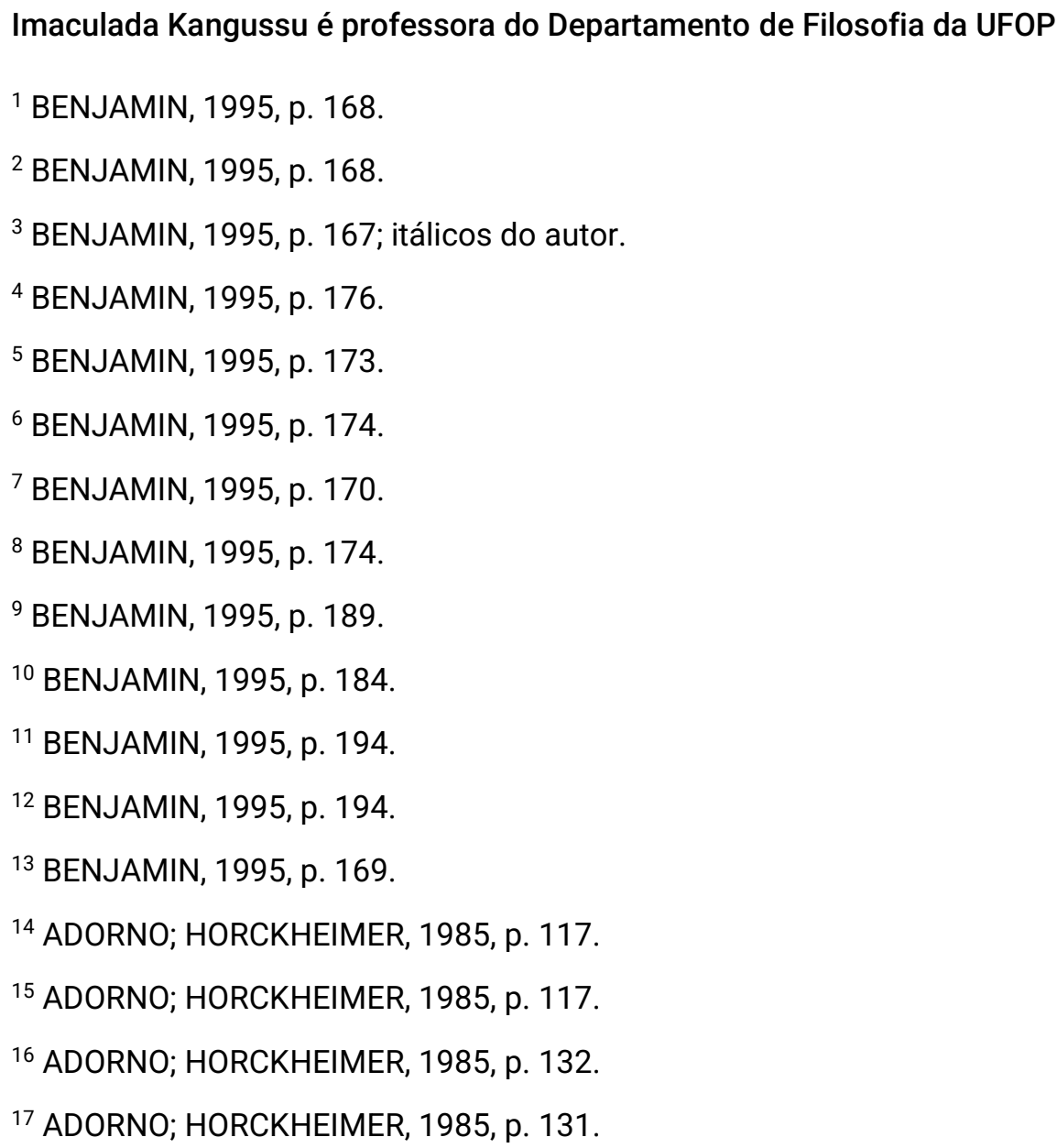


18 ADORNO; HORCKHEIMER, 1985, p. 143. Sobre o papel apaziguador da cultura, cf. Benjamin, Tese VII "Sobre o conceito de história"; e Herbert Marcuse, "Sobre o caráter afirmativo da cultura".

19 ? No cristianismo, talvez o maior evento transformador na história do ocidente (conforme Alain Badiou em L'Être et l'Événement), vale lembrar, a palavra foi "amor". 